\title{
An empirical analysis of airport efficiency: the Croatian case
}

\author{
Danijela Rabar ${ }^{1, \dagger}$, Robert Zenzerović ${ }^{1}$ and Josip Šajrih ${ }^{2}$ \\ ${ }^{1}$ Faculty of Economics and Tourism "Dr. Mijo Mirković", Juraj Dobrila University of \\ Pula, Preradovićeva 1/1, 52100 Pula, Croatia \\ E-mail: 〈\{drabar, robert.zenzerovic\}@unipu.hr〉 \\ ${ }^{2}$ Zagrebačka banka d.d., Trg bana Josipa Jelačića 10, Zagreb, Croatia \\ E-mail: 〈josipsajrih@windowslive.com〉
}

\begin{abstract}
The main objective of this paper is to present an empirical application of the DEA method, by proposing an adequate model for determining the relative efficiencies of seven Croatian airports, and by analysing the obtained scores. To highlight different crucial aspects of airport performance in Croatia, four indicators are used for the period 2009-2014: personnel costs/airport throughput unit (ATU), total expenditures excluding personnel costs/ATU and total assets/ATU as input variables, while the output variable is total revenue/ATU.

To overcome certain limitations associated with the relationship between the number of the observed entities and the number of employed variables, and to provide dynamic efficiency results that usually reflect reality better than static ones, window analysis is used as an extension of basic input-oriented DEA models. In general, the findings indicate that, over the observed period, performance rankings change, and, with the exception of the last observed year, the relative performance of Croatian airports is gradually declining. Consequently, the airports of Split, Pula and Zadar were found to be efficient ("best practice" airports) in the four years, and the airports of Zagreb and Osijek in one single year. Based on the efficiency score averaged across the observed period, Split turned out to be most efficient whilst Osijek appeared to be least efficient. Total assets per ATU are identified as the most significant source of inefficiency.

Using both constant and variable returns to scale assumptions, this paper is the first to decompose the technical efficiency of Croatian airports into two components - pure technical efficiency, which reflects the ability of an airport to obtain maximal outputs at an optimal scale, and scale efficiency, which reflects the distance of an observed airport from the most productive scale size. The significance of these results is in the fact that they offer the possibility of directly identifying inefficiency causes, and can serve as a basis for an a posteriori correction of previously made disadvantageous decisions.
\end{abstract}

Keywords: airport performance, Croatian airports, data envelopment analysis, scale efficiency, window analysis

Received: October 1, 2016; accepted: August 13, 2017; available online: November 30, 2017

DOI: $10.17535 /$ crorr. 2017.0030

$\dagger$ Corresponding author 


\section{Introduction}

The airport industry throughout the world is becoming an increasingly important factor in development. The role of airports is particularly important in the countries that rely on tourism. As a capital-intensive industry, airports endeavour to attract as many airlines as possible, often cooperating with local authorities. This is the rule in most Croatian airports that have seasonal traffic pattern. There are seven international airports in Croatia: Zagreb (ZG), Split (ST), Dubrovnik (DU), Zadar (ZD), Pula (PU), Rijeka (RI) and Osijek (OS), the efficiencies of which will be analyzed in this paper. All airports analyzed are state or region/municipality owned with major state ownership.

Measuring the efficiency in the airport industry often includes different nonrelated ratios that give a segmented view of airport performance. Although partial analysis has its purpose, contemporary management requires a more comprehendsive and integrated approach. Such an approach may involve simultaneous evaluation of different types of productivity that can be indirectly achieved by a performance measurement technique and which includes all parameters used to calculate these productivities and, at the same time, provides a comparison of efficiency levels among airports over a period of time. Therefore, the purpose of this paper is to propose Data Envelopment Analysis (DEA) as a suitable efficiency measurement method that satisfies the aforementioned requirements, and to present the results of analyzed efficiencies of airports in Croatia [13].

DEA is a linear programming-based non-parametric technique used for evaluating the relative efficiency of homogenous operating entities or decision-making units (DMUs) on the basis of empirical data on their multiple inputs and outputs. It leads to an efficient frontier determined by the existing DMUs which are identified as best practice units (benchmarks) and given a rating of 1 , whereas the degree of inefficiency of other entities is calculated on the basis of their distances from the efficient frontier and attributed to input excesses and output shortfalls [13]. The first literature survey focusing on DEA applications is the study of Liu et al. [9] that covers DEA papers indexed in the Web of Science database over the period of 32 years (from 1978 through August 2010). The industries in which the DEA is most addressed are banking, healthcare, agriculture and farm, transporttation and education.

International literature reports numerous studies on airport efficiency. What is worth mentioning is an interesting and frequently cited article in which DEA is combined with the stochastic frontier model to analyze and evaluate the operational efficiency of 33 European airports in the period between 1995 and 1997, in order to assess under which returns to scale each airport operates and to determine technical and scale efficiency coefficients [11]. The results imply objectivity, accuracy and practicability of DEA in addressing these issues. Most 
of DEA applications in the airport industry rely on absolute values of traffic and/or financial variables. Martin and Roman [10] included air traffic movements, number of passengers and tons of cargo transported in each airport as output variables, while input variables were introduced as expenditures and classified according to labor, capital and materials. Kakouris et al. [7] set the number of passengers as output and number of employees, number of flights and area of terminals as input variables. Schaar and Sherry [14] showed DEA methods used in airports benchmarking and analyzed seven different studies that used DEA in the airport industry. All of them used absolute values as input variables while there was only one case that used relative measure as an output variable (percentage of on-time operations).

The literature regarding DEA application in measuring airport efficiency and productivity can be considered from several perspectives. Kadziński et al. [6] point to the substantial existing literature on this topic and group the perspectives according to:

- employed models - ranging from the CCR or BCC model for measuring airport efficiency in a single year or season, through to DEA coupled with the Malmquist productivity index to measure changing airport efficiency over a period of a few years, up to the DEA two-stage model that first examines airport efficiencies, and then uses a procedure to bootstrap DEA scores with a regression model for explanatory purposes,

- type of considered inputs - from monetary inputs to those related to terminal services, the movement model, labor and/or airport localization,

- type of considered outputs - again from monetary aspects to those related to terminal services and/or to the movement model, and

- geographical scope - from single countries to continental or intercontinental scope.

To the authors' knowledge, the only reported study applying DEA methodology to the airport business in Croatia is Bezić et al. [2]. Based on two inputs (expenditures and number of employees) and one output (total number of passengers), the paper analyzed the overall efficiency of seven Croatian airports in the year 2008 and over a five-year period covering 2004-2008, utilizing an input-oriented CCR model. The analysis revealed that the average efficiency scores of Croatian airports, except for Dubrovnik and Rijeka, have increased over the observed period.

Since there is an obvious lack of literature on DEA-based efficiency evaluation of Croatian airports, this research can serve as a basis for future related studies, particularly bearing in mind that it is the first to provide a more detailed investigation of the causes behind the results. It also uses relative instead absolute measures of efficiency that better represent efficiency itself and diminish variations in size of variables. 


\section{Data and analytical framework}

In Croatia, there are 23 airports - nine civil, twelve sport and two military airports. The traffic and financial results they achieve on national level are not relevant, except for the seven international out of a total of nine civil airports listed in introduction. This is the main reason we have focused specifically our research on these seven airports.

The selection of airport performance indicators for the purposes of this study was based on the following criteria: importance of human resources and assets used; consideration of finance aspects of air transport efficiency; exact measurability of indicators; availability and accessibility of data on indicators; ensuring timely, comprehensive, understandable and, above all, useful information both for managers and owners of the respective airports.

Taking into account the criteria mentioned, four indicators were selected and included in the analysis. Personnel costs, total expenditures excluding personnel costs (hereinafter, total expenditures) and total assets represent inputs, while total revenue represents the single output. It should be noted that large disparities in the size of Croatian airports cause significant differences in the values of the selected input and output variables. Thus, for, example, personnel costs, total expenditures and total revenue for the airport in Zagreb are on average about forty times higher than those for the airport in Osijek. To mitigate these variations and make comparison more reliable, all four indicators are taken per ATU.

For the purpose of this research, data were collected from airport annual reports as well as from the Croatian Statistical Bureau and Croatian Civil Aviation Agency. Data relates to the period from 2009 to 2014 covering the most challenging period of the Croatian modern economy when GDP was constantly declining. The basic DEA models usually used in applications are CCR [4] and BCC [1]. The first is characterized by constant returns-to-scale (CRS) activities. In order to adapt it to processes with variable returns-to-scale (VRS), by either increasing (IRS) or decreasing (DRS), the CCR model was extended to the BCC model. In addition, a management strategy can be aimed at either reducing the input amounts or at augmenting the output levels, while in both cases keeping the rest of the variables at their original levels. Accordingly, DEA models are molded to reflect input or output-orientation. [13]

Since an improvement in airport performance requires a reduction of all three inputs, as well as an augmentation of output, both model orientations are suitable. Nevertheless, input-orientation is selected as more appropriate for the purpose of this study, since the airports have more control over the inputs than over the output, i.e. more opportunities to reduce inputs used to produce output. Hence, the concept of efficiency will be explained by using input-oriented models. 
Assume there are $n$ DMUs $\left(\mathrm{DMU}_{j}, j=1,2, \ldots, n\right)$ each of which produces $s$ outputs and to produce them uses $m$ inputs. Let $x_{j}=\left\{x_{i j}, i=1,2, \ldots, m\right\}$ and $y_{j}=$ $\left\{y_{r j}, r=1,2, \ldots, s\right\}$ denote the vectors of inputs and outputs, respectively. The data set is then given by two matrices - the $m \times n$ matrix of inputs $X=\left(x_{i j}\right)$ and the $s \times n$ matrix of outputs $Y=\left(y_{r j}\right)$. The following two-phase linear programming procedure is based on [5], pp. 43-46, 87-89, 140-142.

The input-oriented model employed to evaluate the relative efficiency of real $\mathrm{DMU}_{o}(o \in\{1,2, \ldots, n\})$ in the first phase can be formulated using a standard linear programming problem as

$$
\begin{array}{cc}
\min _{\theta, \lambda} \theta \\
\text { subject to } \quad \theta x_{o}-X \lambda \geq 0 \\
Y \lambda \geq y_{o} \\
\lambda \geq 0 \\
e \lambda=1
\end{array}
$$

where $e$ is a row vector with all elements of unity and $\lambda=\left(\lambda_{1}, \lambda_{2}, \ldots, \lambda_{n}\right)$ is the vector of weights used in the linear combination of efficient DMUs that form the projection of $\mathrm{DMU}_{0}$ onto the frontier. Thus, the projection point represents a composite (virtual) DMU, with the vectors of inputs and outputs respectively equal to $X \lambda$ and $Y \lambda$, that is better or at least not worse than the evaluated $\mathrm{DMU}_{0}$. The input-oriented CCR and BCC models consist of conditions (1)-(4) and (1)(5), respectively. Conditions (2), (3) and (4) comprise $m, s$ and $n$ constraints, respectively. When considering Croatian airports, $n$ is $7, m$ is 3 and $s$ is 1 . The last condition (5) distinguishes two models by causing significant differences in their production frontiers. It should be noted that BCC-efficiency is easier to attain than CCR-efficiency since BCC-frontier is closer. Therefore, BCC-efficiency scores are never lower than CCR estimates. Nevertheless, the optimal objective value $\theta^{*}$ is the efficiency score and, for inefficient $\mathrm{DMU}_{o}$, it is also the reduction rate of its inputs $\left(0<\theta^{*} \leq 1\right)$.

The conditions (2) and (3) signify that $(X \lambda, Y \lambda)$ outperforms $\left(\theta^{*} x_{o}, y_{o}\right)$ when $\theta^{*}<$ 1 , and that the input excesses and the output shortfalls are expressed as $s^{-}=\theta x_{o}-X \lambda, \quad s^{+}=Y \lambda-y_{o}$, respectively, with $s^{-} \geq 0, s^{-} \in R^{m}$ and $s^{+} \geq 0, s^{+} \in R^{s}$ for any feasible solution $(\theta, \lambda)$.

This second phase is carried out to detect possible output shortfalls and remaining input excesses, which is realized by maximizing their sum while maintaining $\theta=$ $\theta^{*}$. 
Definition 1 (Efficiency): If an optimal solution $\left(\theta^{*}, \lambda^{*}, s^{-*}, s^{+*}\right)$ obtained in this two-phase process satisfies $\theta^{*}=1$ and has no slack $\left(s^{-*}=0, s^{+*}=0\right)$, then the $\mathrm{DMU}_{\mathrm{o}}$ is called efficient, otherwise it is inefficient.

Definition 2 (Weak Efficiency): If an optimal solution $\left(\theta^{*}, \lambda^{*}\right)$ satisfies $\theta^{*}=$ 1 , then the $\mathrm{DMU}_{\mathrm{o}}$ is called weakly efficient.

Definition 3 (Reference Set): For an inefficient $\mathrm{DMU}_{\mathrm{o}}$, its reference set $E_{o}$ is defined based on an optimal solution $\lambda^{*}$ by $E_{o}=\left\{j \mid \lambda_{j}^{*}>0\right\} \quad(j \in\{1,2, \ldots, n\})$.

An optimal solution can be formulated as

$$
\begin{aligned}
\theta^{*} x_{o} & =\sum_{j \in E_{o}} x_{j} \lambda_{j}^{*}+s^{-*}, \\
y_{o} & =\sum_{j \epsilon_{o}} y_{j} \lambda_{j}^{*}-s^{+*},
\end{aligned}
$$

suggesting that the efficiency of $\mathrm{DMU}_{o}$ can be improved by reducing the input values, at first radially using the ratio $\theta^{*}$ and then non-radially eliminating the input excesses $s^{-*}$, and also by augmenting output values using the output shortfalls $s^{+*}$. The radial improvement of inputs removes technical inefficiency, while the non-radial improvements of inputs and outputs remove mix inefficiency. It can be calculated using the formula called the projection:

$$
\begin{aligned}
& \hat{x}_{o}=\theta^{*} x_{o}-s^{-*}, \\
& \hat{y}_{o}=y_{o}+s^{+*} .
\end{aligned}
$$

The inefficiency of a DMU may arise due to its inefficient operation or the disadvantageous conditions under which it operates, or both. To explore that, the input-oriented CCR and BCC scores should be compared. Since it takes no account of scale effect, the CCR score is called the (global) technical efficiency and denoted as TE. In contrast, the BCC model takes scale effect into account thus expressing the (local) pure technical efficiency denoted as PTE. BCCefficient DMU with a low CCR score is locally but not globally efficient due to its scale size. It is therefore rational to calculate the scale efficiency of a DMU, denoted as SE, as the ratio of the CCR and BCC efficiency measures.

Definition 4 (Scale Efficiency): Let the CCR and BCC scores of a DMU be $\theta_{C C R}^{*}$ and $\theta_{B C C}^{*}$, respectively. The scale efficiency is defined by

$$
S E=\frac{\theta_{C C R}^{*}}{\theta_{B C C}^{*}}
$$


It apparently cannot exceed one. For a CCR-efficient DMU, it is equal to one. Obviously, the formula (6) reveals an efficiency decomposition as

Technical Efficiency $=$ Pure Technical Efficiency $\times$ Scale Efficiency

This decomposition reveals whether the overall technical inefficiency (TE) is caused by inefficient operation (PTE) or disadvantageous conditions (SE) or both. The request for the monitoring airport efficiency patterns, which is exceptionally important for any airport management, leads to the use of window analysis as a time-dependent extension of DEA models. In this case, data for multiple periods are included in the analysis, and each DMU is regarded as if it is a different DMU in each observed period. All the findings in the next section are based on the results of input-oriented CCR and BCC window analysis models.

\section{Empirical results and discussion}

Due care should be exercised in selecting an appropriate returns-to-scale (RTS) type. Knowing the production frontier characteristics of the analyzed process is crucial. Due to the inability of determining the type of RTS with certainty in the case of airport performance, the analysis was carried out under both (CRS and VRS) assumptions. It showed that differences between the results reached by CCR and BCC model were significant. They may be attributed to the return effect with respect to the range of airport activities thus making the BCC model more suitable for describing the analyzed airport activity and for determining the inefficiency sources in the first phase of this research. However, the second step is intended to reveal inefficiency causes, which points to the need for doing calculations and mutual comparisons of different types of inefficiency. Hence, the analysis was carried out under both CRS and VRS assumptions.

The evaluation of relative efficiency of Croatian airports was carried out on empirical data relating to four airport performance indicators over a six-year period from 2009 to 2014. The nature of the selected indicators allowed comparesons on an annual basis.

The window is the period within which the comparisons were carried out, and its duration ranges from one to six years. One window that spans the entire period was used. The relative efficiency scores generated by the input-oriented CCR and BCC models are listed in Table 1.

On average and according to both models, Split is the most efficient airport. It has never scored the worst efficiency result, and was ranked as the best performing airport in even four separate years. According to both models, average airport efficiency is less than the value of one throughout the entire period, meaning that Croatian airports are inefficient in (pure) technical terms if they are analyzed using average values of CCR and BCC scores. The efficiency results differ signifycantly depending on the model, which, in average terms, is most prominent in the 
case of Pula for the years 2013 and 2014. One third (14 out of 42) of the observed entities turned out to be BCC-efficient, mostly in the last year. Only 6 of them were also CCR-efficient. None of the seven airports was efficient throughout the entire period. Dubrovnik and Rijeka were the only continuously inefficient airports, although Dubrovnik according to the CCR model shows the second best average result. On average and according to both models, efficiency scores were highest in the last observed year years were also the years with the highest and lowest number of efficient airports, respectively. At the same time, the disparities among airports, best seen from the absolute and relative differences between the best, the average and the worst efficiency scores, are most pronounced in 2011, again according to both models. It should also be noted that the standard deviations (SD) are generally somewhat lower, as a result of slightly more balanced performance, when observing the same airport in different years than when observing different airports in the same year. This claim is additionally supported by the values of the coefficients of variation (CV).

Table 1 also includes the values of progressive time-weighted means (PTWM) and Fibonacci weighted geometric means (FWGM). The PTWM [8] and the FWGM [3] are the methods to compute a kind of weighted average of a non-empty set of numbers that gives more weight to recent data points and makes it more responsive to the new information. For the period 1 to $T$, a set of relative efficiency values, say $e_{t}, t=1, \ldots, T$ is considered.

The progressive time-weighted mean can be defined as

$$
\mathrm{PTWM}=\sum_{t=1}^{T} w_{t} e_{t}
$$

where $w_{t}=2 t /\left(T^{2}+T\right), t=1, \ldots, T$ are associated non-negative normalized weights. The Fibonacci weighted geometric mean can be defined as

$$
\mathrm{FWGM}=\operatorname{Exp}\left(\frac{\sum_{t=1}^{T} w_{t} \ln e_{t}}{\sum_{t=1}^{T} w_{t}}\right)
$$

where $w=\{0,0.146,0.236,0.382,0.5,0.618, \ldots\}$ are the associated Fibonacci weights. Obviously, $w_{t}<w_{t+1}, \forall t$, which implies that more emphasis is placed on the recent data points than its immediate past. Moreover, the FWGM completely ignores the initial point.

\footnotetext{
* Data on Zagreb airport efficiency should be taken with caution. Namely, in 2012, a concession was granted over the airport and the investment began realization in 2014 which had a big influence on revenues which increased significantly but not on account of flying and related operations.
} 
In our case, the period spans from 1 (2009) to 6 (2014). As can be seen from Table 1, PTWM and FWGM expectedly alter initial rankings in favor of the airports, the performance of which has been improving in recent years.

In window analysis model, each airport is represented by six entities - one for each of the observed years. Due to the need to mutual distinguish them, the name of each entity should consist of the airport name and the corresponding year. Table 2 displays the findings of the BCC model regarding the reference sets. The table is designed to provide two types of results, depending on whether it is analyzed by rows or by columns. Thus, each table row corresponds to one efficient airport in one year, and contains its reference set frequencies in each of the observed years together with the list of the corresponding inefficient entities. Thus, for example, the airport in Split due to its performance characteristics for the year 2012 (row Split-2012) is a member of four reference sets - Dubrovnik in 2009, Rijeka in 2013 and Osijek in 2010 and 2013. On the other hand, each table column corresponds to one year of observation and, by synthesizing data from a particular column, the reference set for each airport that was inefficient in that particular year can be reconstructed. Thus, for example, the reference set for the airport in Zagreb in the year 2010 consists of four entities - Pula and Zadar in 2010 and Split in 2011 and 2014.

Despite being inefficient in 2010 and 2013, Split sets an example by serving as a reference for the largest number of inefficient airports and particularly stands out in terms of its performance in the year 2014. Interestingly enough, and bearing in mind the earlier observation of an airport's relative efficiency across different periods of time, there are evidently cases where an airport that was efficient in one period appears as the reference to itself in an inefficient period. Such cases show that a particular airport operating inefficiently in a certain period may refer to its previous performance from another period. It is also clear that an efficient year may become a reference to more than one inefficient years. At the same time, an inefficient year may have more than one efficient year which should serve as a reference model. The airport in Pula is a suitable example for illustrating these points. Its performance in 2010 is a reference for performance in 2012 and 2013, while both 2010 and 2014 are representative for 2013. 


\begin{tabular}{|c|c|c|c|c|c|c|c|c|c|c|c|c|c|c|c|c|}
\hline $8 \subseteq$ & : & 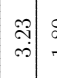 & 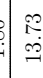 & & \begin{tabular}{l|l}
2 \\
\hdashline \\
\hdashline \\
\hdashline
\end{tabular} & & & & & & $\left|\begin{array}{c}\infty \\
0 \\
\infty \\
\infty\end{array}\right|$ & & \begin{tabular}{c:c}
$\mathcal{C}$ \\
\hdashline \\
$\infty$
\end{tabular} & 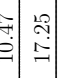 & & \\
\hline हि & $\begin{array}{l}\text { 웜 } \\
\stackrel{0}{0} \\
0\end{array}$ & 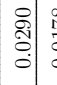 & : & 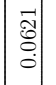 & & & & & & & $\mid$\begin{tabular}{l|}
0 \\
7 \\
0 \\
0 \\
0
\end{tabular} & 㲵 & $\mid$\begin{tabular}{l|}
$\overrightarrow{0}$ \\
0 \\
0 \\
0 \\
0
\end{tabular} & 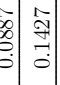 & & \\
\hline 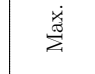 & -1 & - & & 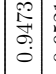 & 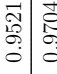 & & & & & & 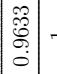 & -- & --1 & 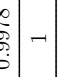 & & \\
\hline 豆 & 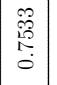 & 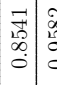 & 音 & $\left|\begin{array}{c}0 \\
0 \\
0 \\
0 \\
0\end{array}\right|$ & 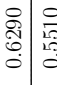 & & & & & & \begin{tabular}{|c|c|}
$\vec{t}$ & \\
0 & $\vdots$ \\
0 & $\vdots$ \\
0 & $\vdots$
\end{tabular} & 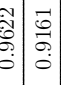 & 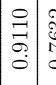 & 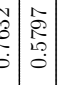 & & \\
\hline 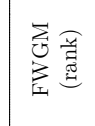 & 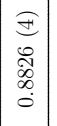 & 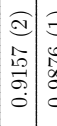 & 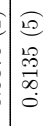 & 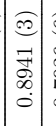 & \begin{tabular}{l|l}
0 & \\
0 & \\
0 \\
0
\end{tabular} & & & & & & 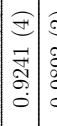 & 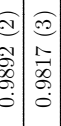 & 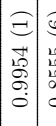 & \begin{tabular}{ll|}
0 & $\mathbb{E}$ \\
0 & 0 \\
0 & 0 \\
0 & 0 \\
0 & 0 \\
0 & 0
\end{tabular} & & \\
\hline 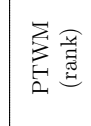 & 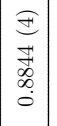 & 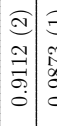 & 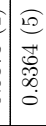 & 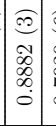 & & & & & & & 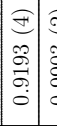 & 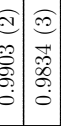 & $\mid \begin{array}{l}0 \\
0 \\
0 \\
0 \\
0 \\
0 \\
0\end{array}$ & 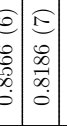 & & \\
\hline 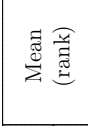 & 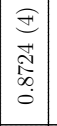 & 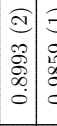 & 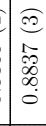 & $\mid \begin{array}{l}0 \\
0 \\
7 \\
0 \\
0 \\
0 \\
0\end{array}$ & 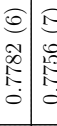 & & & & & & 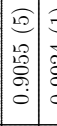 & 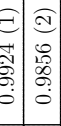 & 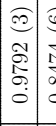 & 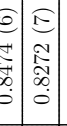 & 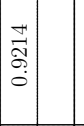 & \\
\hline$\vec{\sim}$ & -1 & - & 总 & 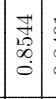 & 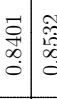 & 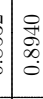 & $\mid$ & $\neg$ & . & 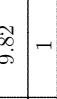 & : & $-\rightarrow$ & -7 & 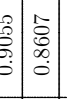 & 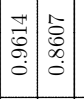 & \\
\hline : & 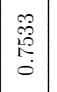 & 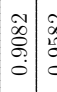 & \begin{tabular}{|ll}
0 \\
$\vdots$ \\
0
\end{tabular} & 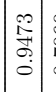 & & 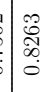 & $\left|\begin{array}{|c}0 \\
0 \\
0 \\
0 \\
0\end{array}\right|$ & 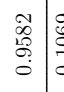 & 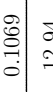 & & 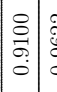 & 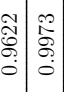 & & 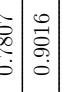 & 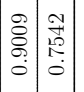 & \\
\hline & $\mid \begin{array}{c}0 \\
\infty \\
\infty \\
\infty \\
0\end{array}$ & $\mid \begin{array}{l}\overrightarrow{3} \\
\vec{a} \\
\dot{0} \\
\dot{0}\end{array}$ & $\mid \begin{array}{c}+1 \\
0.0 \\
0 \\
0\end{array}$ & 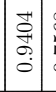 & 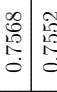 & 离 & 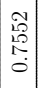 & $-\neg$ & \begin{tabular}{l|l} 
\\
\end{tabular} & & $\mid \begin{array}{l}0 \\
0 \\
0 \\
0 \\
0 \\
0 \\
0\end{array}$ & $-\begin{array}{l}\vec{b} \\
\dot{b} \\
\dot{b}\end{array}$ & - & 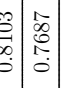 & \begin{tabular}{|c|c|c}
0 & 1 \\
0 & 0 \\
0 & 0 \\
0 & 0 \\
0 & 0
\end{tabular} & $-1-1 \begin{array}{l}\pi \\
0 \\
0 \\
0 \\
0\end{array}$ \\
\hline नี & 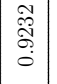 & $\left.\mid \begin{array}{c}0 \\
0 \\
0 \\
0 \\
0\end{array}\right]$ & & 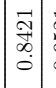 & 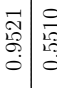 & 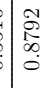 & 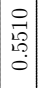 & $-\rightarrow$ & 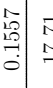 & & $\left.\mid \begin{array}{c}1 \\
0 \\
0 \\
0 \\
0 \\
0\end{array}\right]$ & $-\rightarrow$ & 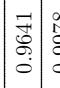 & 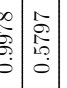 & 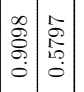 & 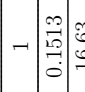 \\
\hline ํํํ & 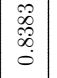 & \begin{tabular}{|c|c|c|c}
0 & 0 \\
0 & 0 \\
0 & 0 \\
0 & 0 & 0
\end{tabular} & & $\mid \begin{array}{c}\infty \\
0 \\
0 \\
0 \\
0 \\
0\end{array}$ & 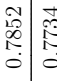 & $\begin{array}{l}\overrightarrow{0} \\
\vdots \\
\infty \\
0 \\
0\end{array}$ & 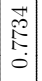 & $-\mid$ & 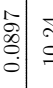 & & 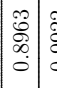 & 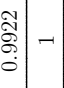 & - & 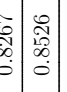 & 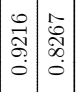 & $-1-\frac{3}{2}$ \\
\hline ठ্. & 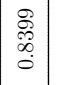 & 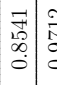 & 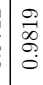 & $\left|\begin{array}{c}0 \\
0 \\
0 \\
0 \\
0\end{array}\right|$ & 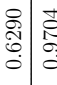 & $\begin{array}{l}1 \\
0 \\
0 \\
0 \\
0 \\
0\end{array}$ & $\mid$ & 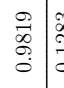 & 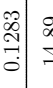 & 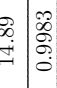 & 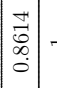 & --- & \begin{tabular}{|l|}
0 \\
$\vec{a}$ \\
0 \\
0
\end{tabular} & 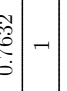 & 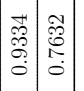 & 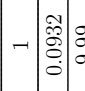 \\
\hline 害 & 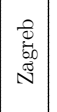 & 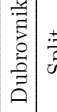 & 2 & 离 & \begin{tabular}{lll}
$\frac{3}{8}$ \\
\hdashline
\end{tabular} & 常 & $\underline{\xi}$ & 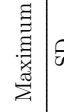 & & 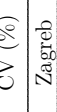 & 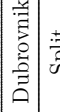 & 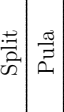 & 恚 & 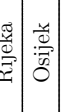 & 荡 & 䝮 \\
\hline$\vec{z}$ & & & & & & & & & & & & & & & & \\
\hline
\end{tabular}

Table 1: Comparison of CCR and BCC input-oriented efficiency scores 


\begin{tabular}{|c|c|c|c|c|c|c|c|c|}
\hline \multirow{3}{*}{$\begin{array}{l}\text { Efficient } \\
\text { airport }\end{array}$} & \multicolumn{8}{|c|}{ Reference set frequency } \\
\hline & \multicolumn{6}{|c|}{ Year } & \multirow{2}{*}{$\Sigma$} & \multirow{2}{*}{$\begin{array}{l}\text { To- } \\
\text { tal } \\
\end{array}$} \\
\hline & 2009 & 2010 & 2011 & 2012 & 2013 & 2014 & & \\
\hline Zagreb-2014 & $\begin{array}{c}1 \\
Z G\end{array}$ & $\begin{array}{c}1 \\
\mathrm{DU}\end{array}$ & $\begin{array}{c}2 \\
\text { DU, OS }\end{array}$ & $\begin{array}{c}1 \\
\mathrm{DU}\end{array}$ & ${ }^{2}{ }^{2}, \mathrm{DU}$ & $\begin{array}{c}2 \\
\mathrm{DU} \\
\mathrm{OS}\end{array}$ & 9 & \\
\hline \multicolumn{8}{|l|}{ Zagreb } & 9 \\
\hline Split-2009 & 0 & 0 & $\begin{array}{c}1 \\
\mathrm{ZG}\end{array}$ & $\begin{array}{c}1 \\
\mathrm{ZG}\end{array}$ & 0 & 0 & 2 & \\
\hline Split-2011 & 0 & $\begin{array}{c}3 \\
\mathrm{ZG}, \\
\mathrm{ST}, \mathrm{RI}\end{array}$ & $\begin{array}{c}1 \\
\mathrm{RI}\end{array}$ & $\begin{array}{c}1 \\
\mathrm{RI}\end{array}$ & $\begin{array}{c}1 \\
\mathrm{ST}\end{array}$ & $\begin{array}{c}1 \\
\mathrm{RI}\end{array}$ & 7 & \\
\hline Split-2012 & $\begin{array}{c}1 \\
\mathrm{DU}\end{array}$ & $\begin{array}{c}1 \\
\text { OS } \\
\end{array}$ & 0 & 0 & $\begin{array}{c}2 \\
\text { RI, OS }\end{array}$ & 0 & 4 & \\
\hline Split-2014 & $\begin{array}{c}3 \\
\text { ZG, } \\
\text { DU, } \\
\text { ZD }\end{array}$ & $\begin{array}{c}3 \\
\text { ZG, } \\
\text { DU, } \\
\text { ST }\end{array}$ & $\begin{array}{c}4 \\
\mathrm{ZG}, \mathrm{DU} \\
\mathrm{ZD}, \mathrm{OS}\end{array}$ & $\begin{array}{c}3 \\
\text { ZG, } \\
\text { DU, OS }\end{array}$ & $\begin{array}{c}3 \\
\text { DU, } \\
\text { ST, RI }\end{array}$ & $\begin{array}{c}2 \\
\mathrm{DU} \\
\mathrm{OS}\end{array}$ & $\begin{array}{l}1 \\
8\end{array}$ & \\
\hline \multicolumn{8}{|l|}{ Split } & 31 \\
\hline Pula-2009 & 0 & 0 & 0 & $\begin{array}{c}1 \\
\text { Pula }\end{array}$ & 0 & 0 & 1 & \\
\hline Pula-2010 & $\begin{array}{c}2 \\
\mathrm{ZD} \\
\mathrm{RI}\end{array}$ & $\begin{array}{c}3 \\
\text { ZG, } \\
\text { ST, RI }\end{array}$ & $\begin{array}{c}1 \\
\mathrm{RI}\end{array}$ & $\begin{array}{c}2 \\
\mathrm{PU}, \mathrm{RI}\end{array}$ & $\stackrel{2}{\mathrm{ST}, \mathrm{PU}}$ & $\begin{array}{c}1 \\
\mathrm{RI}\end{array}$ & $\begin{array}{l}1 \\
1\end{array}$ & \\
\hline Pula-2011 & 0 & 0 & $\begin{array}{c}1 \\
\mathrm{ZG} \\
\end{array}$ & $\begin{array}{c}1 \\
\mathrm{ZG} \\
\end{array}$ & $\begin{array}{c}1 \\
\mathrm{ZG} \\
\end{array}$ & 0 & 3 & \\
\hline Pula-2014 & 0 & 0 & 0 & 0 & $\begin{array}{c}1 \\
\mathrm{PU}\end{array}$ & 0 & 1 & \\
\hline \multicolumn{8}{|l|}{ Pula } & 16 \\
\hline Zadar-2010 & $\begin{array}{c}2 \\
\mathrm{DU} \\
\mathrm{ZD} \\
\end{array}$ & $\begin{array}{c}2 \\
\mathrm{ZG}, \\
\mathrm{ST}\end{array}$ & $\begin{array}{c}1 \\
\mathrm{ZD}\end{array}$ & $\begin{array}{c}2 \\
\mathrm{PU}, \mathrm{OS}\end{array}$ & $\stackrel{2}{\mathrm{ST}, \mathrm{RI}}$ & $\begin{array}{c}1 \\
\mathrm{RI}\end{array}$ & $\begin{array}{l}1 \\
0\end{array}$ & \\
\hline Zadar-2012 & $\begin{array}{c}1 \\
\mathrm{ZD}\end{array}$ & $\begin{array}{c}1 \\
\mathrm{DU}\end{array}$ & $\begin{array}{c}3 \\
\mathrm{DU}, \mathrm{ZD} \\
\mathrm{OS}\end{array}$ & $\begin{array}{c}3 \\
\mathrm{DU}, \\
\mathrm{PU}, \mathrm{OS}\end{array}$ & 0 & $\begin{array}{c}1 \\
\text { OS }\end{array}$ & 9 & \\
\hline Zadar-2013 & 0 & 0 & 0 & 0 & 0 & 0 & 0 & \\
\hline Zadar-2014 & 0 & 0 & 0 & 0 & 0 & 0 & 0 & \\
\hline \multicolumn{8}{|l|}{ Zadar } & 19 \\
\hline
\end{tabular}




\begin{tabular}{|l|c|c|c|c|c|c|c|c|}
\hline Osijek-2009 & 1 & 1 & 0 & 0 & 2 & 1 & 5 & \\
\hline Osijek & ZG & OS & 0 & DU, OS & DU & \\
\hline
\end{tabular}

Table 2: Reference set frequency in the BCC model

Using data envelopment analysis, the respective inefficiency sources, together with amounts of their contribution to inefficiency and proposed improvements, should be identified. This valuable information serves as the starting point for setting goals and making appropriate decisions. Since the BCC model emerged as the more suitable model for this analysis, the proposed improvements based on the CCR model are not considered important, and therefore are omitted.

Unlike basic DEA models, window analysis does not provide inefficiency sources and amounts of their contribution to inefficiency. Hence, a new model was constructed [12]. Four data sets on four selected indicators, one for each of the years examined, were included in the basic model for each airport. Thus, each of the 42 is treated as a separate entity. The construction of this model is justified because it calculates additional crucial results, while not affecting relative efficiency scores identified by window analysis that uses a single six-year window. To provide insight into the extent of inefficiency, the differences between projected and empirical values of each indicator are averaged across inefficient airports and displayed in Table 3. They represent inefficiencies that can be decomposed into radial and non-radial components and eliminated by conducting the previously described two-phase procedure. To illustrate this decomposition, Table 3 also presents the proposed input and output improvements averaged across all airports. For example, in 2014, the BCC mean efficiency score was 0.961347, indicating that on average the airports have a 3.87\% BCC-inefficiency $(3.87=(1$ $\left.-0.961347)^{*} 100\right)$. To operate efficiently, the first phase requires that the airports remove technical inefficiency using management techniques in order to decrease all three inputs by $3.87 \%$ and maintain the original output amounts (based on the previously mentioned radial reduction of inputs by the ratio $\theta^{*}$ ). Total assets represent the greatest input excess, with an average required decrease of $19.09 \%$. The percentage difference indicates that overall efficiency cannot be accomplished by solely eliminating technical inefficiency. Therefore, after decreasing all three inputs radially, and to avoid further losses and inefficiency in relation to the benchmarks, in the second phase the airports should remove the mix inefficiency through further input reduction. The different percentages of improvements required for eliminating inefficiency mean that, when considering total assets, the mix inefficiency is more pronounced than technical inefficiency for the majority of inefficient airports in a particular year. At the same time, when it comes to personnel costs, the situation is reversed. It is also evident that total expenditures, as the third input, cause no mix inefficiency, while total revenue, as the only output, do not cause any inefficiency. 


\begin{tabular}{|c|c|c|c|c|c|c|c|c|}
\hline \multicolumn{9}{|c|}{ Proposed input and output improvements per airport (\%) } \\
\hline \multicolumn{2}{|l|}{ Year } & 2009 & 2010 & 2011 & 2012 & 2013 & 2014 & Mean \\
\hline \multirow[t]{3}{*}{ Inputs } & $\begin{array}{l}\text { Personnel } \\
\text { costs }\end{array}$ & -12.85 & -12.54 & -13.80 & -14.24 & -12.18 & -4.24 & -11.64 \\
\hline & $\begin{array}{l}\text { Total } \\
\text { expenditure } \\
\mathrm{S}\end{array}$ & -6.66 & -7.84 & -9.02 & -9.84 & -15.85 & -3.87 & -8.85 \\
\hline & Total assets & -16.92 & -23.29 & -25.82 & -26.81 & -23.94 & -19.09 & -22.65 \\
\hline Output & $\begin{array}{l}\text { Total } \\
\text { revenue }\end{array}$ & 0.43 & 0.00 & 0.00 & 0.00 & 0.62 & 0.00 & 0.18 \\
\hline \multicolumn{9}{|c|}{ Proposed input and output improvements per inefficient airport (\%) } \\
\hline \multicolumn{2}{|l|}{ Year } & 2009 & 2010 & 2011 & 2012 & 2013 & 2014 & Mean \\
\hline \multirow[t]{3}{*}{ Inputs } & $\begin{array}{l}\text { Personnel } \\
\text { costs }\end{array}$ & -22.49 & -17.56 & -19.32 & -19.93 & -14.21 & -9.88 & -17.46 \\
\hline & $\begin{array}{l}\text { Total } \\
\text { expenditure } \\
\mathrm{S}\end{array}$ & -11.65 & -10.98 & -12.63 & -13.78 & -18.49 & -9.02 & -13.27 \\
\hline & Total assets & -29.61 & -32.61 & -36.15 & -37.53 & -27.94 & -44.54 & -33.97 \\
\hline Output & $\begin{array}{l}\text { Total } \\
\text { revenue }\end{array}$ & 0.76 & 0.00 & 0.00 & 0.00 & 0.73 & 0.00 & 0.26 \\
\hline
\end{tabular}

Table 3: Inefficiency sources and average amounts in the BCC model

Apparently, a total asset is the indicator that, without exception, most signifycantly affects efficiency during the entire period. The focus of management should be to manage assets more appropriately, although it requires taking into account that the airports are a capital intensive, highly regulated industry that has significant assets requiring the fulfilment of regulations. Notably, selecting the model orientation, on average, has a greater influence on the inputs than on the output. 


\begin{tabular}{|c|c|c|c|c|c|c|c|c|c|c|}
\hline & 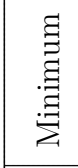 & 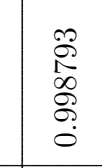 & 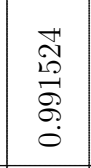 & $\begin{array}{l}0 \\
D \\
1 \\
2 \\
2 \\
0 \\
0 \\
\end{array}$ & 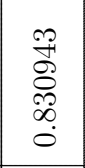 & $\begin{array}{l}\mathscr{0} \\
0 \\
0 \\
0 \\
\infty \\
0 \\
0\end{array}$ & 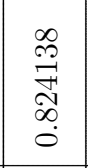 & 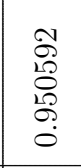 & & \\
\hline & 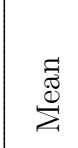 & 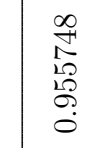 & 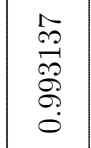 & 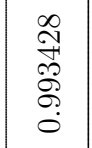 & $\begin{array}{l}7 \\
-7 \\
0 \\
8 \\
0 \\
0 \\
0 \\
0\end{array}$ & $\begin{array}{l}\text { N } \\
\stackrel{N}{1} \\
\infty \\
\infty \\
0 \\
0\end{array}$ & $\begin{array}{l}\hat{0} \\
\mathscr{0} \\
\infty \\
\sigma \\
0 \\
0\end{array}$ & 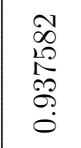 & 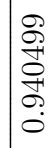 & \\
\hline & $\frac{ \pm}{\curvearrowright}$ & 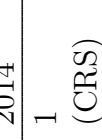 & 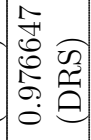 & $-\widetilde{2}$ & 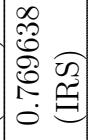 & 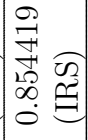 & 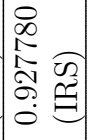 & 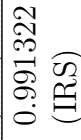 & $\mid \begin{array}{l}0 \\
2 \\
2 \\
0 \\
0\end{array}$ & . \\
\hline & & 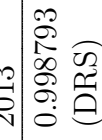 & 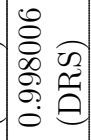 & $\left|\begin{array}{ll}0 & \\
2 & \\
2 & 0 \\
2 & 0 \\
0 & \ddots \\
0 & \Xi\end{array}\right|$ & 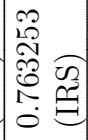 & 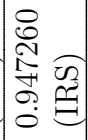 & 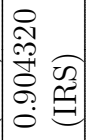 & 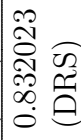 & 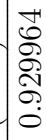 & 总 \\
\hline & $\stackrel{\overbrace{}}{\tilde{\sigma}}$ & 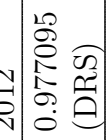 & 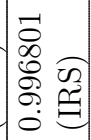 & 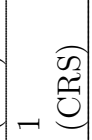 & 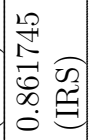 & 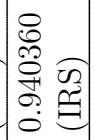 & 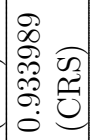 & 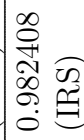 & $\begin{array}{l}\stackrel{0}{D} \\
\stackrel{D}{N} \\
\frac{N}{\sigma} \\
0\end{array}$ & 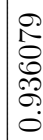 \\
\hline & $\bar{\sim}$ & 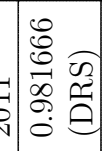 & 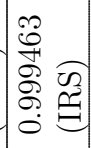 & 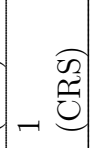 & -0 & 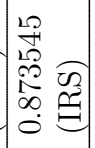 & 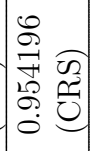 & 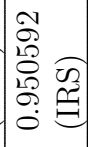 & 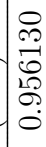 & \begin{tabular}{l}
$\infty$ \\
$\stackrel{0}{N}$ \\
\multirow{2}{0}{} \\
0 \\
0 \\
0
\end{tabular} \\
\hline & 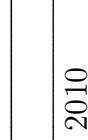 & 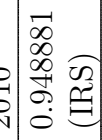 & 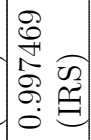 & 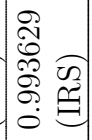 & $\begin{array}{r}0 \\
-0 \\
-0\end{array}$ & 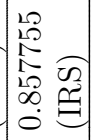 & 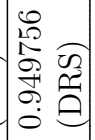 & 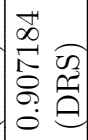 & $\left\{\begin{array}{l}0 \\
0 \\
+1 \\
0 \\
8 \\
0 \\
0\end{array}\right.$ & 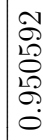 \\
\hline & 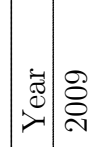 & 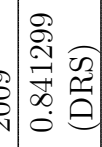 & 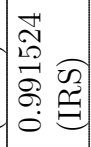 & 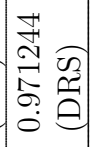 & 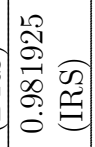 & 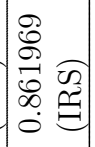 & 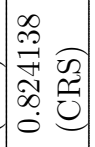 & 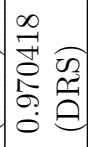 & 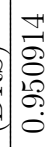 & 离 \\
\hline & : & 党 & 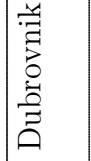 & 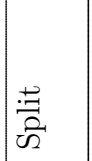 & $\frac{\pi}{\vec{z}}$ & $\begin{array}{l}\frac{\pi}{\pi} \\
\frac{\pi}{N}\end{array}$ & 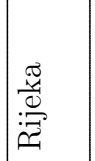 & 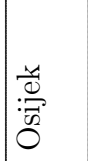 & 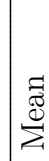 & \\
\hline
\end{tabular}

Table 4: Scale efficiency scores

The causes of relative inefficiency of Croatian airports can be local or global. The scale inefficiencies have to be assessed in order to resolve this dilemma, which in the case of input-oriented models are also input-oriented. They are shown in Table 
4 for all 42 entities. The types of returns to scale were also identified. They can be found in the same table.

When comparing the empirical results presented in Tables 1 and 4, a wide diversity of calculated efficiencies among the airports is noticed. The mean values of overall technical, pure technical and scale efficiency are approximately 0.87 , 0.92 and 0.94 , respectively. This indicates on average similar shares of pure technical and scale inefficiency in the overall inefficiency of Croatian airports. These shares differ significantly from one airport to another. Two opposite examples are briefly presented to illustrate the problem. The first example is Zadar which has higher pure technical scores rather than scale scores during the entire investigated period. This difference is most significant in the second and final year, meaning that the overall inefficiency of this airport is largely due to scale inefficiency. The airport in Zadar exhibits increasing returns to scale, i.e. it operates under a suboptimal scale. In order to reach the optimal scale, Zadar needs to expand its operations. On the other hand, in the case of Dubrovnik, the impact of scale efficiency on overall efficiency is negligible compared to the impact of pure technical efficiency, also during the entire period of investigation. In order to eliminate the pure technical efficiency, airport management should adopt best practices implemented at efficient airports. Finally, both mentioned airports produce outcomes less than optimally required (best practice) from given resources. All of the above-mentioned points to the necessity of a more detailed investigation of the causes behind the results and the obligation of implementing appropriate measures for improving airport efficiency. This particularly includes analyzing expenditures and productivity of assets and employees.

\section{Concluding remarks}

An evaluation of relative efficiency of Croatian airports was conducted based on the reciprocal performance comparison of the seven major Croatian airports, according to $\mathrm{CCR}$ and $\mathrm{BCC}$ window analysis. In analysis, the same set of three input and one output variables were used for the six-year period. The research results suggest that pure technical and scale inefficiency for Croatian airports, on average, contribute about the same to the overall inefficiency. Split Airport was found to be one airport that had the highest average efficiency over the observed period and can be used as a benchmark for other airports. Research has shown that there are possibilities of increasing efficiency levels in Croatian airports. The average overall technical inefficiency can be reduced by $13 \%$, if operating at optimal scales and eliminating pure technical inefficiencies. A total asset is the key input variable that most significantly affects efficiency during the entire period, hence efforts by management should be taken to improve its usage and particularly maximize the output i.e. revenues. 
The most important implications either for subsequent revision of already made disadvantageous decisions or for completely new managerial decisions can be drawn from the objectives identified by the appropriate DEA model. More precisely, management at each airport is provided with exact information on the inefficiency sources and amounts of their contribution to inefficiency, as well as to whether inefficiency causes are of local or global nature. In this way, decisions can be more easily directed to ensure that desired objectives are achieved.

Future research in this field could rely on a longer period of analysis as well as including airports of similar size and operating in similar economic surroundings. This could broaden the conclusions drawn in this research and expand insights into improving airport efficiency.

\section{References}

[1] Banker, R. D., Charnes, A. and Cooper, W. W. (1984). Some models for estimating technical and scale inefficiencies in data envelopment analysis. Management Science, 30(9), 1078-1092. DOI: 10.1287/mnsc.30.9.1078.

[2] Bezić, H., Šegota, A. and Vojvodić, K. (2010, January). Measuring the efficiency of Croatian airports. In the 5th International Conference Economic development perspectives of SEE region in the global recession context-ICES (pp. 14-15).

[3] Charles, V., Kumar, M., Zegarra, L. F. and Avolio, B. (2011). Benchmarking Peruvian banks using data envelopment analysis. Journal of CENTRUM Cathedra, 4(2), 147-164.

[4] Charnes, A., Cooper, W. W. and Rhodes, E. (1978). Measuring the efficiency of decision making units. European Journal of Operational Research, 2(6), 429-44. DOI: 10.1016/0377-2217(78)90138-8.

[5] Cooper, W. W., Seiford, L. M. and Tone, K. (2006). Introduction to Data Envelopment Analysis and Its Uses: With DEA-Solver Software and References. New York: Springer.

[6] Kadziński, M., Labijak, A. and Napieraj, M. (2017). Integrated framework for robustness analysis using ratio-based efficiency model with application to evaluation of Polish airports. Omega, 67, 1-18.

[7] Kakouris, A., Katarelos, E., Pantelidis, A. (2014). Assessment of efficiency of Greek airports. Data envelopment analysis and performance measurement. Proceedings of $11^{\text {th }}$ International Conference of DEA, ISBN: 978185449477 1.

[8] Kumar, M. and Vincent, C. (2011). Benchmarking Indian banks using DEA in post reform period: a progressive time-weighted mean approach. The Service Industries Journal, 31(14), 2455-2485.

[9] Liu, J. S., Lu, L. Y., Lu, W.-M. and Lin, B. J. (2013). A survey of DEA applications. Omega, 41(5), 893-902. DOI: 10.1016/j.omega.2012.11.004. 
[10] Martin, J. C., Roman, C. (2001). An application of DEA to measure the efficiency of Spanish airports prior to privatization. Journal of Air Transport Management, 7, 149-157.

[11] Pels, E., Nijkamp, P., \& Rietveld, P. (2003). Inefficiencies and scale economies of European airport operations. Transportation Research Part E: Logistics and Transportation Review, 39(5), 341-361.

[12] Rabar, D. (2013). Assessment of regional efficiency in Croatia using data envelopment analysis. Croatian Operational Research Review, 4, 76-88.

[13] Rabar, D. (2015). Setting key performance targets for Croatian shipyards. Croatian Operational Research Review, 6, 279-291.

[14] Schaar, D., Sherry, L. (2008). Comparison of Data Envelopment Analysis Methods Used in Airport Benchmarking. Available at: http://catsr.vse.gmu. edu/pubs/Schaar_Sherry_ICRAT.pdf. 10.03.2016. 